\title{
REAÇÃO DE PORTA-ENXERTOS HÍBRIDOS AO Citrus tristeza virus
}

\section{PAULO E. MEISSNER FILHO ${ }^{1}$, WALTER DOS S. SOARES FILHO ${ }^{1}$, KARINNA V. C. VELAME ${ }^{2}$, ELIZIO P. DIAMANTINO ${ }^{3} \&$ MARIA S. A. S. DIAMANTINO ${ }^{2}$}

\author{
${ }^{1}$ Embrapa Mandioca e Fruticultura Tropical, Cx. Postal 007, CEP 44.380-000, Cruz das Almas, BA, \\ fax (075) 621-2149, e-mail: meissner@ cnpmf.embrapa.br; ${ }^{2}$ Mestrado Escola de Agronomia da UFBA; \\ 3Plantbem Comércio e Representações Ltda, Rua P. Morais, 60, CEP 45015-600, Vitória da Conquista, BA
}

(Aceito para publicação em 15/03/2002)

Autor para correspondência: Paulo Ernesto Meissner Filho

MEISSNER FILHO, P.E., SOARES FILHO, W. dos S., VELAME, K.V.C., DIAMANTINO, E.P. \& DIAMANTINO, M.S.A.S. Reação de porta-enxertos híbridos ao Citrus tristeza virus. Fitopatologia Brasileira 27:312-315. 2002.

\section{RESUMO}

A tristeza causada pelo vírus da tristeza dos citros (Citrus tristeza virus, CTV) é uma das principais viroses dos citros (Citrus spp.) no Brasil. Alguns autores têm utilizado a intensidade de caneluras produzidas nos ramos para selecionar plantas com resistência ao vírus. Neste trabalho foi avaliada a reação de porta-enxertos híbridos, provenientes do programa de melhoramento genético de citros da Embrapa Mandioca e Fruticultura ao CTV e elaboradas duas escalas, uma fotográfica e outra diagramática, para quantificação de resistência ao CTV. Entre os porta-enxertos avaliados, a maioria apresentou poucas caneluras, sendo portanto considerados resistentes à tristeza. Verificou-se a manutenção da resistência ao vírus nos híbridos produzidos a partir de progenitores que possuíam algum nível de resistência.

Palavras chaves adicionais: CTV, escala de notas, "stem pitting", caneluras.

\section{ABSTRACT \\ Reaction of hybrid rootstocks to Citrus tristeza virus}

Tristeza caused by Citrus tristeza virus (CTV) is one of the main virus diseases of citrus (Citrus spp.) in Brazil. Some authors have used the intensity of stem pitting symptoms to select resistant plants to tristeza. This work evalueated the reaction of hybrid rootstocks from the citrus breeding program of Embrapa Cassava and Tropical Fruits. Two scales, for hybrid rootstock evaluation of resistance to CTV were elaborated, one photographic and the other diagrammatic. The majority of the analyzed rootstocks showed a low number of stem pitting and was considered resistant to the virus. Resistance was maintained in hybrids when the parent plants presented resistance to $\mathrm{CTV}$.
No Brasil, em 1999 foram produzidas 22.768 mil toneladas de laranja (Citrus spp.), destacando-se os Estados de São Paulo, Sergipe, Bahia e Minas Gerais como os principais produtores (Estanislau et al., 2001). Diversas doenças influenciam a produção de citros no país, sendo a tristeza, causada pelo vírus da tristeza dos citros (Citrus tristeza virus, CTV), pertencente à família Closteroviridae, gênero Closterovirus, um dos problemas fitossanitários importantes da cultura (Rosseti, 2001). Esta virose ocasionou na década de 40, no Brasil, a perda de milhões de árvores (Koller, 1994).

O CTV é transmitido de forma semi-persistente pelo pulgão Toxoptera citricidus Kirk. e por material propagativo infetado (Whiteside et al., 1993; Rossetti et al., 1993; Murphy et al., 1995). A sintomatologia da tristeza é variável, dependendo da estirpe presente e da combinação copa/portaenxerto afetada (Müller, 1976; Whiteside et al., 1993).

Alguns autores têm correlacionado a maior virulência de estirpes com a produção de caneluras nos ramos e troncos das plantas infetadas. Desta forma, Salibe \& Cereda (1984); Salibe et al. (1992) e Van Vuuren et al. (1993) elaboraram escalas de notas, utilizando a intensidade de caneluras apresentadas para a seleção de estirpes com menor virulência para uso em pré-imunização e plantas melhores adaptadas a determinadas regiões. Porém, estas escalas são de difícil uso porque não vêm acompanhadas de uma escala fotográfica ou diagramática, sendo muito subjetiva a descrição de cada nota.

No Brasil, o vírus e o vetor são endêmicos, assim, a alternativa para controle da tristeza é a utilização de espécies/ variedades resistentes ou pré-imunizadas com estirpes fracas (Müller \& Costa, 1973; Müller, 1976).

Este trabalho visou avaliar porta-enxertos híbridos e desenvolver uma escala fotográfica/diagramática, de fácil uso, para determinação da resistência de citros à tristeza.

Os experimentos foram conduzidos no Banco Ativo de Germoplasma (BAG) de Citros e no campo de portaenxertos híbridos de citros da Embrapa Mandioca e Fruticultura, em Cruz das Almas (BA).

Para a confecção da escala de notas (fotográfica e diagramática) foram coletados ramos, com cerca de $20 \mathrm{~cm}$ de comprimento, em diferentes acessos do BAG. Os ramos foram autoclavados durante um minuto para facilitar a retirada da 
casca. Em função da intensidade de caneluras presentes, os ramos foram distribuídos em cinco grupos, sendo então preparada uma escala de notas que refletisse a intensidade de caneluras presentes, na qual a nota 1 corresponde à ausência de caneluras, nota 2 presença de caneluras esparsas, nota 3 número intermediário de caneluras, nota 4 várias caneluras superficiais ou poucas caneluras profundas e nota 5 toda a superfície do ramo coberta por caneluras superficiais ou profundas (Figuras 1 e 2).

Utilizando a escala proposta foram avaliados os

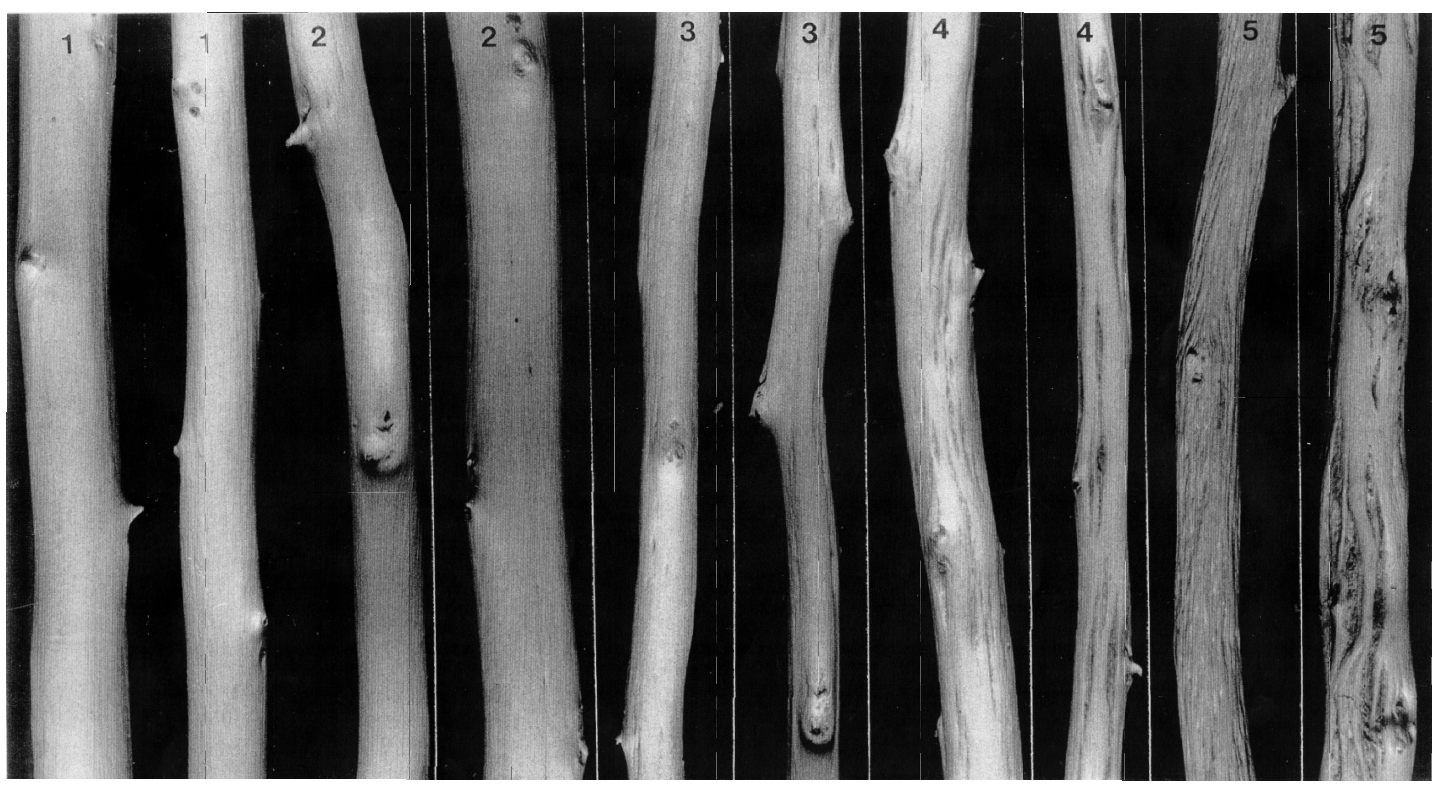

FIG. 1 - Escala de notas com fotografias para a avaliação de resistência à tristeza dos citros (Citrus spp.). 1 = ausência de caneluras, 2 = presença de caneluras esparsas, 3 = número intermediário de caneluras, $4=$ várias caneluras superficiais ou poucas caneluras profundas e 5 = toda a superfície do ramo coberta por caneluras superficiais ou profundas.

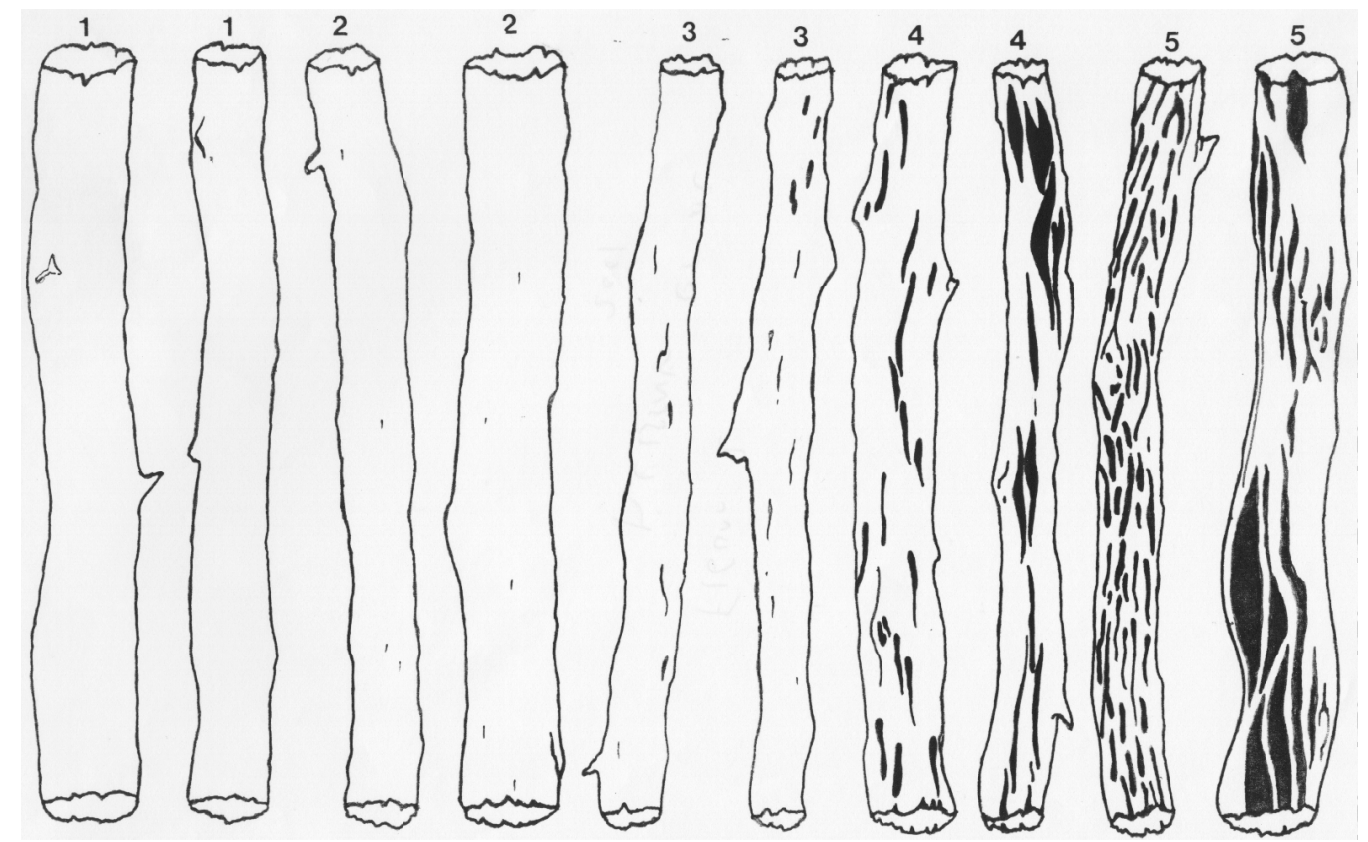

FIG. 2 - Escala de notas diagramática para avaliação de resistência à tristeza dos citros (Citrus spp.). $1=$ ausência de caneluras, 2 = presença de caneluras esparsas, 3 = número intermediário de caneluras, 4 = várias caneluras superficiais ou poucas caneluras profundas e 5 = toda a superfície do ramo coberta por caneluras superficiais ou profundas. 
híbridos de porta-enxertos produzidos pelo programa de melhoramento genético de citros da Embrapa Mandioca e Fruticultura (Soares Filho et al., 1997). As amostras foram coletadas de híbridos estabelecidos há três anos no campo, retirando-se dez ramos com cerca de $20 \mathrm{~cm}$ de comprimento de cada planta, amostrando-se todos os quadrantes dela. Os ramos coletados foram descascados e avaliados por três pessoas diferentes usando a escala elaborada, obtendo-se uma nota média para cada híbrido.
A maior parte dos cruzamentos nos quais foi utilizado o Poncirus trifoliata (L.) Raf. originaram híbridos com elevada resistência, notas 1 e 2 ao CTV (Tabela 1), o que era esperado, uma vez que esta espécie é imune aos isolados da tristeza (Carvalho et al., 1997). Os híbridos provenientes de cruzamentos nos quais foram utilizados limão 'Volkameriano' (Citrus volkameriana Ten. et Pasq.), limão 'Cravo' ( $C$. limonia Osb.) e laranja 'Palmeiras' [C. sinensis (L.) Osb.] também manifestaram um nível elevado de resistência, notas

TABELA 1 - Reação de porta-enxertos híbridos ao vírus da tristeza dos citros (Citrus tristeza virus, CTV). Cruz das Almas, 1997

\begin{tabular}{|c|c|c|c|c|c|c|c|}
\hline HÍBRIDO* & MÉDIA ** & HÍBRIDO & MÉDIA & HÍBRIDO & MÉDIA & HÍBRIDO & MÉDIA \\
\hline H 001 & 1,00 & H 073 & 1,18 & H 177 & 2,83 & KP 007 & 1,32 \\
\hline H 002 & 1,00 & Н 074 & 1,22 & H 179 & 1,15 & KP 008 & 1,59 \\
\hline Н 003 & 1,00 & Н 075 & 1,00 & H 180 & 1,18 & KP 010 & 1,44 \\
\hline Н 004 & 1,11 & Н 076 & 2,75 & H 183 & 1,07 & KP 013 & 1,48 \\
\hline H 005 & 1,00 & Н 077 & 1,25 & H 189 & 1,04 & KP 015 & 1,62 \\
\hline Н 006 & 1,00 & Н 079 & 1,07 & H 204 & 1,00 & KP 016 & 1,18 \\
\hline Н 007 & 1,00 & Н 080 & 1,00 & KC 001 & 1,63 & KP 017 & 2,13 \\
\hline Н 008 & 1,11 & Н 082 & 1,00 & KC 003 & 1,00 & KP 020 & 1,14 \\
\hline Н 009 & 1,41 & Н 083 & 1,00 & $\mathrm{KC} 006$ & 1,00 & KP 021 & 1,44 \\
\hline Н 011 & 1,17 & Н 086 & 1,33 & KC 008 & 1,08 & KP 024 & 1,00 \\
\hline Н 012 & 1,00 & Н 089 & 1,33 & KC 009 & 1,53 & KP 025 & 4,15 \\
\hline Н 014 & 1,00 & Н 090 & 1,00 & $\mathrm{KC} 010$ & 1,31 & KP 027 & 1,58 \\
\hline Н 015 & 1,00 & Н 010 & 1,46 & KC 013 & 1,05 & KP 029 & 1,04 \\
\hline Н 022 & 1,00 & H 102 & 1,33 & KC 014 & 2,48 & KP 031 & 1,00 \\
\hline Н 023 & 1,33 & H 104 & 1,33 & $\mathrm{KC} 015$ & 1,00 & KP 032 & 1,73 \\
\hline Н 027 & 1,33 & Н 107 & 2,00 & KC 017 & 1,07 & KP 036 & 1,20 \\
\hline Н 032 & 1,33 & H 108 & 1,37 & KC 018 & 1,79 & KP 037 & 2,11 \\
\hline Н 033 & 1,22 & H 110 & 1,20 & KC 019 & 1,00 & KP 038 & 1,22 \\
\hline H 034 & 2,00 & H 116 & 1,63 & KC 021 & 1,03 & KV 001 & 1,58 \\
\hline Н 037 & 1,33 & $\mathrm{H} 121 \mathrm{~A}$ & 1,11 & KC 022 & 1,00 & KV 002 & 3,54 \\
\hline Н 038 & 1,33 & H 122 & 1,15 & KC 024 & 1,09 & KV 003 & 1,22 \\
\hline Н 040 & 1,41 & H 123 & 1,33 & KC 026 & 1,11 & KV 005 & 1,70 \\
\hline Н 044 & 1,16 & H 125 & 1,60 & KC 029 & 2,74 & KV 006 & 2,00 \\
\hline Н 045 & 1,27 & H 126 & 1,00 & KC 030 & 1,11 & KV 007 & 1,44 \\
\hline Н 046 & 1,59 & H 128 & 1,50 & KC 031 & 1,15 & KV 008 & 4,10 \\
\hline Н 048 & 1,33 & H 131 & 1,33 & KC 034 & 1,17 & KV 009 & 3,62 \\
\hline Н 052 & 1,26 & Н 133 & 1,33 & KC 038 & 1,30 & KV 011 & 2,71 \\
\hline H $052 \mathrm{~A}$ & 1,50 & H 134 & 1,00 & KC 039 & 1,38 & KV 012 & 3,54 \\
\hline Н 054 & 1,00 & H 135 & 1,00 & $\mathrm{KC} 043$ & 3,27 & KV 014 & 1,74 \\
\hline Н 057 & 1,00 & H 138 & 1,19 & KC 048 & 1,03 & $\mathrm{~S}(\mathrm{TR} \times \mathrm{C}) 002$ & 1,53 \\
\hline Н 059 & 1,22 & Н 139 & 1,44 & KC 049 & 1,41 & S (TR x C) 003 & 1,33 \\
\hline H 060 & 1,00 & H 143 & 1,33 & $\mathrm{KC} 050$ & 1,33 & $\mathrm{~S}(\mathrm{TR} \times \mathrm{C}) 005$ & 1,42 \\
\hline Н 062 & 2,67 & H 144 & 1,41 & KC 052 & 1,17 & $\mathrm{~S}(\mathrm{TR} \times \mathrm{C}) 006$ & 1,20 \\
\hline Н 063 & 3,55 & H 147 & 1,11 & KC 059 & 1,14 & $\mathrm{~S}(\mathrm{TR} \times \mathrm{C}) 007$ & 1,00 \\
\hline Н 064 & 2,49 & H 152 & 1,15 & KC 061 & 1,07 & S (TR x C) 009 & 1,33 \\
\hline Н 065 & 3,54 & H 016A & 1,26 & $\mathrm{KC} 069$ & 1,05 & $\mathrm{~S}(\mathrm{TR} \times \mathrm{C}) 010$ & 1,27 \\
\hline Н 068 & 1,14 & H 161 & 1,26 & KC 074 & 1,17 & $\mathrm{~S}(\mathrm{TR} \times \mathrm{C}) 011$ & 1,50 \\
\hline Н 070 & 1,12 & H 164 & 1,07 & KP 001 & 3,00 & $\mathrm{~S}(\mathrm{TR} \times \mathrm{C}) 012$ & 1,49 \\
\hline Н 071 & 1,12 & H 166 & 1,37 & KP 004 & 1,44 & $\mathrm{~S}(\mathrm{TR} \times \mathrm{C}) 015$ & 2,33 \\
\hline
\end{tabular}

*H = híbridos trifoliados obtidos de cruzamentos envolvendo tangerina 'Cleópatra' (Citrus reshini Hort. ex Tan.), limão 'Cravo' (C. limonia Osb.) e laranja 'Pêra' [C. sinensis (L.) Osb.] como parentais femininos e Poncirus trifoliata $($ L.) Raf. e híbridos desta espécie como parentais masculinos; C = limão 'Cravo' (C. limonia Osb.); $\mathrm{P}=$ laranja 'Palmeiras' (C. sinensis); $\mathrm{V}=$ laranja 'Valência' (C. sinensis); $\mathrm{K}=$ limão 'Volkameriano' (C. volkameriana Ten. et Pasq.); $\mathrm{S}=$ tangerina 'Sunki' (C. sunki Hort. ex Tan.); TR: (Poncirus trifoliata).

**Média de três leituras em cada ramo ( 10/planta), usando-se a seguinte escala de notas: $1=$ ausência de caneluras; $2=$ presença de caneluras esparsas; $3=$ número intermediário de caneluras; 4 = várias caneluras superficiais ou poucas caneluras profundas e $5=$ toda a superfície do ramo coberta por caneluras superficiais ou profundas. 
1 e 2, (Tabela 1). Reação adequada já que são espécies resistentes ao vírus. Os híbridos de limão 'Volkameriano' e laranja 'Valência' exibiram reações variáveis, notas 1 a 4, (Tabela 1) (Koller, 1994). Dentre os híbridos avaliados, verificou-se que a maioria apresentou notas entre 1 e 2 , sendo portanto considerados resistentes às estirpes de CTV presentes na região.

Em São Paulo, analisando germoplasma de citros e sua reação ao CTV, Carvalho et al. (1997) observaram que os isolados mais virulentos ocorreram em laranjas doces, enquanto nos limões verdadeiros ( $C$. limon Burm.) e na tangerina 'Cleópatra' ( C. reshni Hort. ex Tan.) predominaram isolados menos virulentos e $P$. trifoliata não foi infetado pelo vírus. A ocorrência de isolados virulentos, nos genótipos analisados, parece ter correlação com a resistência das plantas ao vírus.

Os híbridos mais promissores serão avaliados em outras regiões, quanto à sua resistência a estirpes de CTV predominantes nestes locais, visando a recomendação de novos porta-enxertos para citros.

\section{AGRADECIMENTOS}

Agradecemos aos colegas Hermes P. Santos Filho, Maria J. Silva, André F. M. Rocha e Cristiane de J. Barbosa pelas sugestões relativas à confecção da escala de notas para CTV. Ao colega Osmar Nickel pela revisão do manuscrito e ao amigo Luciano de Souza Santos pelo desenho da escala diagramática.

\section{REFERÊNCIAS BIBLIOGRÁFICAS}

CARVALHO, S.A., MACHADO, M.A., BAPTISTA, C.R., MÜLLER, G.W. \& SILVÉRIO, J.C. Caracterização biológica de isolados do vírus da tristeza em diferentes espécies e variedades cítricas. Fitopatologia Brasileira 22:79-84. 1997. ESTANISLAU, M.L.L., BOTEON, M., CANÇADO JÚNIOR, F.L. \& PAIVA, B.M. de. Laranjas e sucos: aspectos econômicos.
Informe Agropecuário 22:8-20. 2001.

KOLLER, O.C. Citricultura:laranja, limão e tangerina. Porto Alegre. Editora Rígel. 1994.

MÜLlER, G.W. A Tristeza dos Citros. Summa Phytopathologica 2:245-63. 1976.

MÜLLER, G.W. \& COSTA, A.S. Métodos de seleção de estirpes fracas do vírus da Tristeza. Anais, II Congresso Brasileiro de Fruticultura, Viçosa, MG. 1973. pp. 287-295.

MURPHY, F.A., FAUQUET, C.M., BISHOP, D.H.L., GHABRIAL, S.A., JARVIS, A.W., MARTELLI, G.P., MAYO, M.A. \& SUMMERS, M.D. Virus taxonomy-classification and nomenclature of viruses. Archives of Virology 10:497. 1995. (Abstract).

ROSSETI, V.V. Doenças causadas por vírus e semelhantes. In: Rosseti, V.V. (Ed.) Manual ilustrado de doenças dos citros. Piracicaba:Fealq/Fundecitrus. 2001. pp.59-91.

ROSSETTI, V., MÜLLER, G.W. \& COSTA, A.S. Doenças dos citros causadas por algas, fungos, bactérias e vírus. Campinas. Fundação Cargill. 1993.

SALIBE, A.A. \& CEREDA, E. Incidência de exocorte, sorose e "stem pitting"de tristeza em cultivares de baixa acidez. Summa Phytopathologica 10:86-87. 1984.

SALIBE, A.B., TUBELIS, A. \& SALIBE, A.A. Incidência de caneluras ou "stem pitting" de tristeza em mudas cítricas produzidas com borbulhas de matrizes selecionadas. Summa Phytopathologica 18:9. 1992. (Resumo).

SOARES FILHO, W. dos S., VILARINHOS, A. D., CUNHA SOBRINHO, A.P. da, OLIVEIRA, A.A.R. de, SOUZA, A. da S., CRUZ, J.L., MORAIS, L.S., CASTRO NETO, M.T. de, GUERRA FILHO, M. dos S., CUNHA, M.A.P. da, PASSOS, O.S., MEISSNER FILHO, P.E. \& OLIVEIRA, R.P. de Programa de melhoramento genético de citros da EMBRAPA-CNPMF: obtenção de híbridos. Cruz das Almas, BA:EMBRAPA/CNPMF, Documentos, 74, 1997.

VAN VUUREN, S.P., COLLINS, R.P. \& GRAÇA, J.V. da. Evaluation of citrus tristeza virus isolates for cross protection of grapefruit in South Africa. Plant Disease. 77:24-28. 1993.

WHITESIDE, J.O., GARNSEY, S.M \& TIMMER, L.W. Compendium of Citrus Diseases. $2^{\text {nd }}$ ed. Saint Paul. APS Press. 1993. 